\title{
Proteome characteristics of liver tissue from patients with parenteral nutrition- associated liver disease
}

\author{
Gulisudumu Maitiabola ${ }^{1 \dagger}$, Feng Tian ${ }^{1 \dagger}$, Haifeng Sun ${ }^{1 \dagger}$, Li Zhang ${ }^{1}$, Xuejin Gao ${ }^{1}$, Bin Xue ${ }^{2^{*}}$ and Xinying Wang ${ }^{1 *}$
}

\begin{abstract}
Background: Parenteral nutrition (PN)-associated liver disease (PNALD) is a common and life-threatening complication in patients receiving PN. However, its definitive etiology is not yet clear. Therefore, performed proteomic analyses of human liver tissue to explore the same.

Methods: Liver tissue was derived and compared across selected patients with $(n=3)$ /without $(n=4)$ PNALD via isobaric Tag for Relative and Absolute Quantitation (iTRAQ)-based quantitative proteomics. Bioinformatics analysis was performed using Gene Ontology (GO) and Kyoto Encyclopedia of Genes and Genomes (KEGG) databases to explore the mechanisms of PNALD based on differentially expressed proteins (DEPS). The essential proteins that were differentially expressed between the two groups were explored and verified by western blotting.

Results: A total of 112 proteins were found to be differentially expressed, of which 73 were downregulated, and 39 were upregulated in the PNALD group. Bioinformatics analysis showed DEPs to be associated with mitochondrial oxidative phosphorylation (mainly involved in mitochondrial respiratory chain complex I assembly), hepatic glycolipid metabolism (involved primarily in glycogen formation and gluconeogenesis), and oxidative stress (mainly involved in antioxidant change).

Conclusion: Overall, our results indicated that mitochondrial energy metabolism impairment, hepatic glycolipid metabolism disorder, and excessive oxidative stress injury might explain the comprehensive mechanism underlying PNALD. Moreover, we have provided multiple potential targets for further exploring the PNALD mechanism.
\end{abstract}

Keywords: Parenteral nutrition associated liver disease, Mitochondria, Oxidative phosphorylation, Metabolic disorder, Oxidative stress

\section{Background}

Total parenteral nutrition (TPN) is a vital therapeutic measure for patients with impaired gut function, including short bowel syndrome, severe inflammatory bowel disease, or chronic idiopathic intestinal pseudo-

\footnotetext{
* Correspondence: xuebin@nju.edu.cn; wangxinying@nju.edu.cn

${ }^{\dagger}$ Gulisudumu Maitiabola, Feng Tian and Haifeng Sun contributed equally to this work.

${ }^{2}$ Core Laboratory, Sir Run Run Hospital, Nanjing Medical University, Nanjing 211166, China

'Department of General Surgery, Jinling Hospital, Medical School of Nanjing University, East Zhongshan Road 305, Nanjing 210002, P.R. China
}

obstruction [1-3]. Parenteral nutrition-associated liver disease (PNALD) is one of the most common complications of long-term parenteral nutrition (PN), which severely impairs the physical health of patients, and is the primary factor limiting long-term PN therapy.

The incidence of PNALD in infants receiving long-term parenteral nutrition is between 25 and $60 \%$, and that in adults is between 15 and $40 \%$ [4]. In adults, a history of PNALD is characterized by elevated liver enzymes and associated steatosis, with ensuing complications such as steatohepatitis, cholestatic hepatitis, as well as fibrosis and

(c) The Author(s). 2020 Open Access This article is licensed under a Creative Commons Attribution 4.0 International License, which permits use, sharing, adaptation, distribution and reproduction in any medium or format, as long as you give appropriate credit to the original author(s) and the source, provide a link to the Creative Commons licence, and indicate if changes were made. The images or other third party material in this article are included in the article's Creative Commons licence, unless indicated otherwise in a credit line to the material. If material is not included in the article's Creative Commons licence and your intended use is not permitted by statutory regulation or exceeds the permitted use, you will need to obtain permission directly from the copyright holder. To view a copy of this licence, visit http://creativecommons.org/licenses/by/4.0/ The Creative Commons Public Domain Dedication waiver (http://creativecommons.org/publicdomain/zero/1.0/) applies to the data made available in this article, unless otherwise stated in a credit line to the data. 
cirrhosis [5]. Most biochemical abnormalities of the liver can be reversed by weaning at an early stage of PNALD, whereas most of the advanced pathophysiological changes are irreversible, resulting in cirrhosis, decompensated liver disease, liver failure, and liver carcinoma. In these patients, PNALD progresses to end-stage liver disease, requiring combined intestinal and liver transplant [6-8].

Research on the mechanistic pathways and ameliorative modalities in PNALD is a significant focus in the field of gastroenterology and hepatology. Several theories have been proposed, for instance,the components of PN directly harm the liver or that the absence of enteral nutrition disrupts the enterohepatic axis leading to liver injur y[9]. However, the pathophysiology and etiology of PNALD remain unclear, and there have been very few studies exploring the overall protein expression in liver tissue of patients with PNALD.

Proteomics is a large-scale comprehensive study of proteins, including information on protein abundance and modification, along with their interacting networks [10]. Studies regarding PNALD have been limited to the transcriptomic level in mouse models [11], and, to the best of our knowledge, neither genomic nor proteomics studies on PNALD have been conducted till date. More importantly, no prior studies have explored the use of human specimens to understand this disease. Studies are, thus, required that use liver samples from PNALD patients for proteomics research, which would be more conducive to solving clinical problems. Based on this consideration, this study aimed to explore the possible mechanisms underlying the pathogenesis of PNALD, as well as identify potential therapeutic targets by performing hepatic proteomics in patients with or without PNALD in the present study.

\section{Materials and methods Subjects}

Patients with diagnostic percutaneous or intraoperative liver biopsy were recruited from the Department of General Surgery, Jinling Hospital, Medical School of Nanjing University. Liver tissue was obtained from seven patients, with $(n=3)$ and without $(n=4)$ PNALD. Disease information and clinical characteristics were collected from the electronic database and detailed in Table 1 . Subjects with PNALD had liver enzymes elevated 1.5 times the upper limit of normal, in the absence of any other cause, such as viral hepatitis or drug-induced changes [12]. All subjects gave their informed consent for inclusion before they participated in the study. The study was approved by the Ethics Committee of the Jinling hospital, Medical School of Nanjing University (2017NZGKJ-071).

\section{Sample preparation}

The tissues were ground in liquid nitrogen. One milliliter of lysis buffer (7 M urea, 4\% SDS, 1x Protease Inhibitor Cocktail (Roche Ltd. Basel, Switzerland)) was added to samples, followed by sonication on ice and centrifugation at $13000 \mathrm{rpm}$ for $10 \mathrm{~min}$ at $4{ }^{\circ} \mathrm{C}$. The supernatant was transferred to a fresh tube.

Table 1 Demographic and Clinical Characteristics of Participants

\begin{tabular}{|c|c|c|c|c|c|c|c|c|}
\hline \multirow{2}{*}{$\begin{array}{l}\text { Group } \\
\text { Characteristic }\end{array}$} & \multicolumn{3}{|l|}{ PNALD } & \multicolumn{5}{|l|}{ Non-PNALD } \\
\hline & Pt. 1 & Pt. 2 & Pt. 3 & Pt. (A) & Pt. (B) & Pt. (C) & Pt. (D) & $\begin{array}{l}\mathrm{P}- \\
\text { value }\end{array}$ \\
\hline Age (yr.) & 58 & 49 & 31 & 46 & 52 & 62 & 38 & 0.5545 \\
\hline Sex & man & man & man & man & man & Woman & Woman & - \\
\hline Weight (kg) & 60 & 61 & 43 & 72 & 76 & 60 & 52 & 0.2604 \\
\hline $\mathrm{BMI}, \mathrm{kg} / \mathrm{m} 2$ & 21.6 & 20.6 & 15.8 & 23.2 & 24.5 & 23.1 & 20.1 & 0.1277 \\
\hline Diagnosis & $\begin{array}{l}\text { short bowel } \\
\text { syndrome }\end{array}$ & $\begin{array}{l}\text { short bowel } \\
\text { syndrome }\end{array}$ & $\begin{array}{l}\text { abdominal } \\
\text { cocoon }\end{array}$ & $\begin{array}{l}\text { hepatic } \\
\text { hemangioma }\end{array}$ & Cholelithiasis & $\begin{array}{l}\text { hepatic } \\
\text { hemangioma }\end{array}$ & $\begin{array}{l}\text { hepatic } \\
\text { hemangioma }\end{array}$ & - \\
\hline $\mathrm{ALT}(\mathrm{U} / \mathrm{L})$ & 136 & 129 & 217 & 22 & 32 & 34 & 31 & 0.0027 \\
\hline AST (U/L) & 132 & 125 & 257 & 26 & 28 & 21 & 29 & 0.0099 \\
\hline GGT (U/L) & 335 & 281 & 458 & 39 & 41 & 36 & 27 & 0.0007 \\
\hline TBIL (umol/L) & 60.7 & 45.4 & 45.5 & 6.9 & 10.2 & 8.3 & 7.7 & 0.0003 \\
\hline $\begin{array}{l}\text { BUN (mmol/ } \\
\text { L) }\end{array}$ & 8.9 & 14.1 & 9.5 & 3.4 & 4.6 & 3.9 & 5.2 & 0.0063 \\
\hline Scr (umol/L) & 50 & 189.8 & 68 & 79 & 83 & 69 & 77 & 0.5187 \\
\hline $\begin{array}{l}\text { Days with } \\
\text { PN }\end{array}$ & 123 & 109 & 138 & 0 & 0 & 0 & 0 & - \\
\hline
\end{tabular}

$A L T$ aspartate aminotransferase, AST alanine aminotransferase, GGT gamma-glutamyl transferase, TBIL total bilirubin, BUN blood urea nitrogen, SCr serum creatinine, Pt patient 


\section{Protein digestion and ITRAQ labeling}

Determine the protein concentration of the supernatant using the BCA protein assay, and then transfer $100 \mu \mathrm{g}$ protein per condition into a new tube and adjust to a final volume of $100 \mu \mathrm{L}$ with $100 \mathrm{mM}$ TEAB (triethylammonium bicarbonate). Add $5 \mu \mathrm{L}$ of the $200 \mathrm{mM}$ DTT and incubate sample at $55^{\circ} \mathrm{C}$ for $1 \mathrm{~h}$, then add $5 \mu \mathrm{L}$ of the $375 \mathrm{mM}$ iodoacetamide to the sample and incubate for $30 \mathrm{~min}$ protected from light at room temperature. For each sample, proteins were precipitated with icecold acetone, and then were redissolved in $20 \mu \mathrm{L}$ TEAB. Then proteins were tryptically digested with sequencegrade modified trypsin (Promega, Madison, WI), and the resultant peptide mixture was labeled using chemicals from the iTRAQ reagent kit. The labeled samples were combined, desalted using C18 SPE column (Sep-Pak C18, Waters, Milford, MA) and dried in vacuo.

\section{High-pH reverse-phase separation}

The peptide mixture was re-dissolved in buffer A (buffer A: $10 \mathrm{mM}$ ammonium formate in water, $\mathrm{pH} 10.0$, adjusted with ammonium hydroxide), and fractionated by high-pH separation using an Acquity UPLC system (Waters Corporation, Milford, MA) connected to a reversephase column (BEH C18 column, $2.1 \mathrm{~mm} \times 150 \mathrm{~mm}$, $1.7 \mu \mathrm{m}, 300 \AA$, Waters Corporation, Milford, MA). The high-pH separation was performed using a linear gradient, starting from $0 \%$ B to $45 \%$ B in $45 \mathrm{~min}$ (B: $10 \mathrm{mM}$ ammonium formate in $90 \% \mathrm{ACN}, \mathrm{pH} 10.0$, adjusted with ammonium hydroxide). The column flow rate was maintained at $250 \mu \mathrm{L} / \mathrm{min}$, and the column temperature was maintained at $45^{\circ} \mathrm{C}$. Twelve fractions were collected, and each was dried in a vacuum concentrator for the next step.

\section{Low-pH nano-HPLC-MS/MS analysis}

Fractions were re-suspended with $32 \mu$ solvent C (C: water with $0.1 \%$ formic acid; D: ACN with $0.1 \%$ formic acid), separated by nanoLC, and analyzed by on-line electrospray tandem mass spectrometry. Experiments were performed on a nanoACQUITY UPLC system (Waters Corporation, Milford, MA) connected to a quadrupole-Orbitrap mass spectrometer (Q-Exactive) (Thermo Fisher Scientific, Bremen, Germany) equipped with an online nano-electrospray ion source. Eightmicroliter peptide sample was loaded onto the trap column (Thermo Fisher Scientific Acclaim PepMap C18, $100 \mu \mathrm{m} \times 2 \mathrm{~cm}$ ), with a flow rate of $10 \mu \mathrm{l} / \mathrm{min}$ for $3 \mathrm{~min}$, and subsequently separated on the analytical column (Acclaim PepMap C18, $75 \mu \mathrm{m} \times 25 \mathrm{~cm}$ ) with a linear gradient, from $5 \% \mathrm{D}$ to $30 \% \mathrm{D}$ in $105 \mathrm{~min}$. The column was cleaned and re-equilibrated to initial conditions for 5 min. The column flow rate was maintained at $300 \mathrm{~nL} /$ min, and the column temperature was maintained at $45^{\circ} \mathrm{C}$. The electrospray voltage of $1.8 \mathrm{kV}$ versus the inlet of the mass spectrometer was used.

The Q-Exactive mass spectrometer was operated in the data-dependent mode to switch automatically between MS and MS/MS acquisition. Survey full-scan MS spectra $(\mathrm{m} / \mathrm{z} 350-1600)$ were acquired with a mass resolution of $70 \mathrm{~K}$, followed by fifteen sequential high-energy collisional dissociations (HCD)-MS/MS scans with a resolution of $17.5 \mathrm{~K}$. In all cases, one Microscan was recorded using a dynamic exclusion of $30 \mathrm{~s}$. MS/MS-fixed first mass was set at 100 .

\section{Database searching and data analysis}

Tandem mass spectra were extracted by Proteome Discoverer software (Thermo Fisher Scientific, version 1.4.0.288). Charge state deconvolution and deisotoping were not performed. All MS/MS samples were analyzed using Mascot (Matrix Science, London, UK; version 2.3). Mascot was set up to search the Uniprot-SwissProt database (Taxonomy: Homo sapiens, 20,245 entries) assuming the digestion enzyme trypsin. Mascot was searched with a fragment ion mass tolerance of $0.050 \mathrm{Da}$ and a parent ion tolerance of 10.0 PPM. Carbamidomethyl of cysteine and iTRAQ 8plex of lysine and the n-terminus were specified in Mascot as fixed modifications. Oxidation of methionine and iTRAQ 8plex of tyrosine were specified in Mascot as a variable modification. Use the percolator algorithm to control peptide level false discovery rates (FDR) lower than $1 \%$. Only unique peptides were used for protein quantification, and the method of normalization on protein median was used to correct experimental bias, the minimum number of proteins that must be observed to allow was set to 1000 . Bioinformatics analysis of the identified proteins was performed, and DEPs were defined in the iTRAQ experiment according to the following criteria: unique peptides $\geq 1, P$-value $<$ 0.05 , fold change $>1.2$ or $<0.8333$ [13]. DEPs were entered into the DAVID (Database for Annotation, Visualization, and Integrated Discovery) database (david. abcc.ncifcrf.gov) for functional classification and GO enrichment analysis [14], and to determine the significant pathways according to the KEGG pathway analysis (www.kegg.jp/kegg/pathway.html). Protein-protein interaction (PPI) networks were generated through the STRING database (v10, string-db.org). Pathway analysis was conducted using Ingenuity Pathway Analysis (IPA) (www.biotree.com.cn Shanghai Biotree biotech Co., Ltd) on the differentially expressed proteins.

\section{Verification of proteins by western blot analysis}

Protein samples were separated by electrophoresis on $12 \%$ SDS-PAGE gel, transferred to polyvinylidene fluoride membranes, blocked with $5 \%$ non-fat milk for $1 \mathrm{~h}$, and incubated with primary antibodies against CYP2B6, 
DDAH1 (Thermo Scientific, Rockford, IL), FABP5 (ProteinTech, Chicago, IL, USA), CAPG, and NDUFA1 (Affinity Bioscience, USA), overnight at $4{ }^{\circ} \mathrm{C}$. Anti-rabbit horseradish peroxidase (HRP)-conjugated antibody was used as a secondary antibody, followed by ECL substrate (Thermo Scientific, Rockford, IL) incubation, and image visualization using Tanon 5200 imaging system (Tanon, China). Gray-scale analysis of the bands was performed using Image software. Data are presented as ratios of the target protein to the internal control.

Statistical analyses - Proteins with $p$-value $<0.05$ and Fold Change $<0.83$ or $>1.2$ were considered as differentially expressed proteins between the two groups. Student's t-test was used for comparison of the difference between groups.

\section{Results}

Comprehensive identification of proteome in human liver tissue

A total of 14,307 peptides and 3337 proteins were identified by iTRAQ analysis. Mass spectrometry results showed 112 differentially expressed proteins (DEPs), of which 73 were down regulated, and 39 were upregulated in the PNALD group (Table S1).
To identify the functional classification of DEPs, this study performed gene ontology analysis according to their molecular functions (MF), biological processes (BP), and cellular components (CC) with the assistance of DAVID Bioinformatics Resources. The top 15 annotations represented in each of the three GO categories are shown in Fig. 1. Majority of enriched categories included mitochondrial and mitochondria-related proteins (Fig. 2a, Table S2; total 27, 16 downregulated and 11 upregulated). Impaired oxidative phosphorylation was the predominant process in PNALD group. Mitochondria are known to be mainly responsible for the oxidative decomposition of dextrose, fat, and protein, for providing energy. Accordingly, the glycolipid metabolism (Fig. 2b, Table S3; total 32, 28 downregulated and 4 upregulated) and amino acid metabolism (Fig. 2c, Table S4; total 22, 15 downregulated and 7 upregulated) were significantly altered between the groups.

\section{Mitochondrial oxidative phosphorylation was impaired in PNALD patients}

Mitochondrial oxidative phosphorylation system is the final biochemical pathway to produce ATP and the maintenance of cell function. Mitochondrial respiratory chain NADH dehydrogenase (complex I) is the most






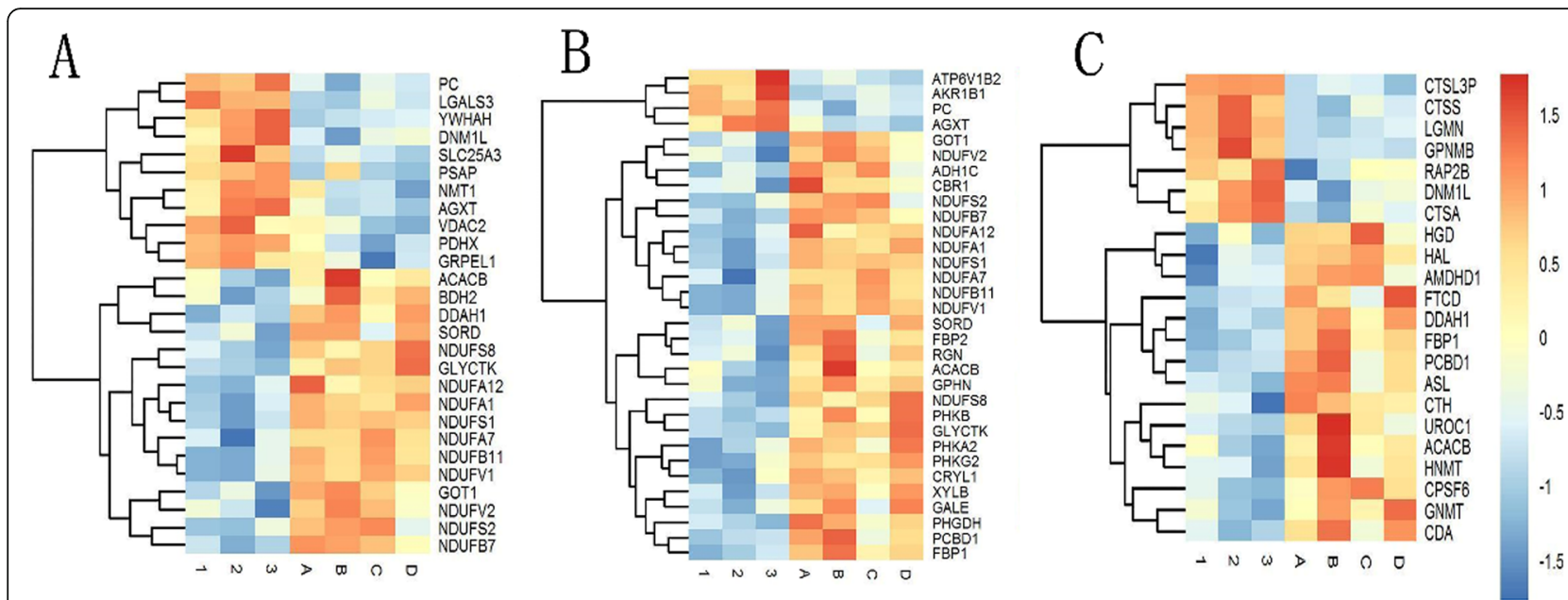

Fig. 2 Heat map of differentially expressed proteins (DEPS) in PNALD and control patient. a: Mitochondrial and mitochondrial-related proteins; b: Glycolipid metabolisms associated proteins; c: Amino acid metabolisms associated proteins. Colored boxes represent upregulation (red) and downregulation (blue) in the PNALD. The color scale shown at the upper right indicates the fold changes in protein expression of all the samples. 1, 2, 3: PNALD group; A, B, C, D: Control group

abundant enzyme in the electron transport chain [15], and is essential for oxidative phosphorylation in mitochondria [16]. Ten subunits of NADH dehydrogenase were found to be downregulated in the PNALD group, including NDUFB11, NDUFB7, NDUFV1, NDUFA7, NDUFV2, NDUFS8, NDUFA1, NDUFS2, NDUFA12, and NDUFS1 (Table S2). Consistent with our hypothesis that mitochondrial oxidative phosphorylation in the liver of patients with PNALD might be impaired, bioinformatics analysis indicated the DEPs to be enriched in mitochondria-associated biological processes (Fig. 3), including mitochondrial electron transport (NADH to ubiquinone), response to oxidative stress, oxidationreduction process, and ATP synthesis-coupled electron transport (Table 2). And the IPA showed that the oxidative phosphorylation was significantly inhibited (Fig. 4). These all results indicated the mitochondrial oxidative phosphorylationwas impaired in PNALD patients.

\section{Hepatic glycolipid metabolism disorder in patients with PNALD}

Liver plays a significant role in the control of glucose homeostasis by regulating various pathways in glucose metabolism, including glycogenesis, glycogenolysis, glycolysis, and gluconeogenesis. In this study, we observed a strong enrichment of DEPs linked to metabolic enzymes. For example, phosphorylase kinases (PHKA2, PHKB, and PHKG2), which stimulate glycogen degradation [17], were downregulated. Fructose 1,6-bisphosphate 1-phosphatases (FBP1 and FBP2), the rate-limiting enzyme in gluconeogenesis [18], were downregulated. Pyruvate carboxylase (PC), which catalyzes the ATP-dependent carboxylation of pyruvate to oxaloacetate, and involved in gluconeogenesis
$[19,20]$, was also found to be downregulated. Consistent with the function of DEPs, bioinformatics analysis indicated that glycogen metabolic process (PHKA2, PHKB, PHKG2, and GNMT) and gluconeogenesis (GOT1, FBP1, FBP2, and PC) might be damaged in PNALD. Besides, we also found some glycolipid metabolism-associated DEPs, including nicotinamide N-methyltransferase (NNMT, upregulated) [21], D-3-phosphoglycerate dehydrogenase (PHGDH, downregulated) [22], and serine/threonine-protein phosphatase (CPPED1, downregulated) [23].

Besides its role in glucose metabolism, the liver plays a pivotal role in lipid metabolism and is the hub of fatty acid metabolism and lipid circulation [24]. Estrogen sulfotransferase (SULT1E1), involved in the process of adipogenesis $[25,26]$, was found to be downregulated and acetyl-CoA carboxylase 2 (ACACB), which inhibits fatty acid oxidation [27], was also downregulated. Further, lipid metabolism associated DEPs, including glycine Nmethyltransferase (GNMT, downregulated) [28-32], fatty acid-binding protein (FABP5, upregulated) [33], cathepsin S (CTSS, upregulated) [34], aldose reductase (AKR1B1, upregulated) [35], and N(G), N(G)-dimethylarginine dimethylaminohydrolase 1 (DDAH1, downregulated) were also identified [36]. These results together indicated PNALD to be related to glycolipid metabolism disorder.

\section{Oxidative stress caused by downregulation of the antioxidant factors may generate PNALD}

Previous reports had shown oxidative stress injury to be one of the significant causes of PNALD. Production of ROS is increased when mitochondrial oxidative phosphorylation is impaired and under circumstances of antioxidant defense 


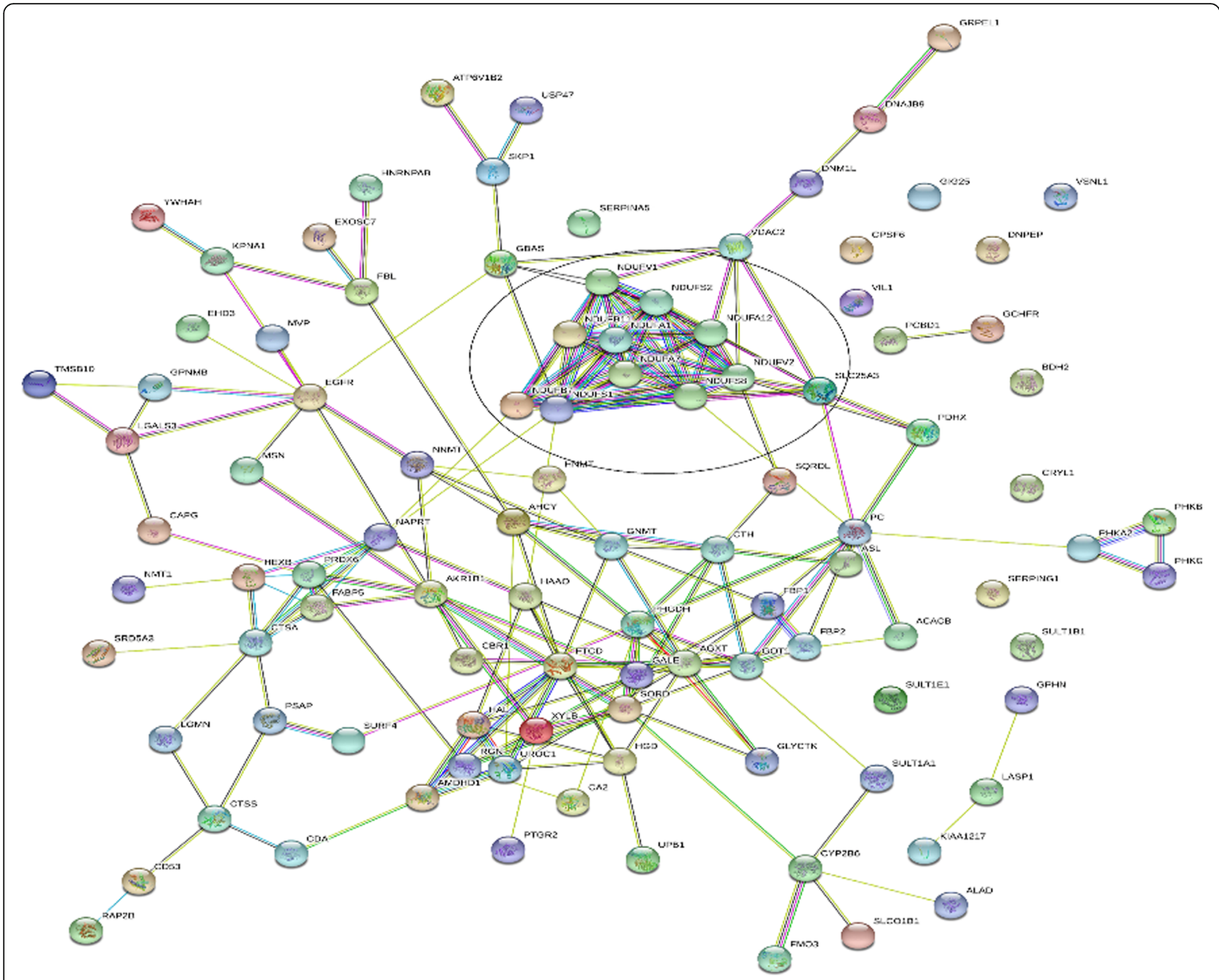

Fig. 3 Protein-protein interaction of differentially-expressed protein for group PNALD vs. control

deficiency [37]. First, the impaired mitochondrial respiratory chain complex I assembly proteins damage the normal process of oxidative phosphorylation in patients with PNALD. Second, various antioxidant factors are downregulated in PNALD. For example, peroxiredoxin-6 (PRDX6, downregulated) is a peroxiredoxin that primarily functions as an antioxidant to scavenge peroxides in biological systems [38], regucalcin (RGN, downregulated) is an antioxidant [39], delta-aminolevulinic acid dehydratase (ALAD, downregulated) is an important antioxidant enzyme, whose inhibition may result in the accumulation of its substrate d-ALA, which in turn is associated with the overproduction of ROS [40], inhibition of PHGDH (downregulated) impairs the synthesis of heme, resulting in the impairment of oxidative phosphorylation and escape of electrons to molecular oxygen generating more ROS [41], inhibition of aspartate aminotransferase (GOT1, downregulated) inhibits the synthesis of the NADPH antioxidan t[42], and DDAH1 (downregulated) deficiency significantly enhances cellular oxidative stress [43]. , Third, we found histidine metabolism-associated proteins (AMDHD1, HNMT, FTCD, HAL, and UROC1) to be downregulated in PNALD. Previous studies had reported the histidine supplementation to inhibit oxidative stress and preserve mitochondrial membrane potential as well as dehydrogenase activity [44]. Moreover, IPA results showed that the "NRF2mediated oxidative stress response", "EIF2 signaling", "PFKFB4 signaling pathway", and "Glutathione mediated detoxification" were suppressed (Fig. S2). Previous studies had reported these pathways all participated in decreasing oxidative stres s[45-48]. Combined with the above results, we can hypothesize that oxidative stress caused by downregulation of the antioxidant factors may also participate in the development of PNALD.

\section{Validation of differential expression proteins by western blotting}

In order to verify the credibility of proteomics, we randomly selected several up- and downregulated DEPs for 
Table. 2 Gene Ontology analysis of mitochondria associated differentially expressed proteins

\begin{tabular}{|c|c|c|c|c|}
\hline \multirow[t]{2}{*}{ Analysis } & \multirow[t]{2}{*}{ Pathway } & \multicolumn{3}{|l|}{ Protein number } \\
\hline & & List & Up & Down \\
\hline \multirow[t]{6}{*}{$\begin{array}{l}\text { Cellular } \\
\text { Component }\end{array}$} & mitochondrion & $\begin{array}{l}\text { NDUFB11, GRPEL1, DNM1L, NDUFB7, PSAP, NDUFA7, ACACB, VDAC2, } \\
\text { NDUFA1, GLYCTK, NMT1, YWHAH, GOT1, NDUFV2, NDUFS8, SLC25A3, } \\
\text { BDH2, DDAH1, NDUFS2, NDUFS1, PC }\end{array}$ & 8 & 13 \\
\hline & mitochondrial respiratory chain complex I & $\begin{array}{l}\text { NDUFB11, NDUFB7, NDUFV1, NDUFA7, NDUFV2, NDUFS8, NDUFA1, } \\
\text { NDUFS2, NDUFA12, NDUFS1 }\end{array}$ & 0 & 10 \\
\hline & mitochondrial inner membrane & $\begin{array}{l}\text { NDUFB11, LGALS3, NDUFB7, NDUFV1, NDUFA7, NDUFV2, SLC25A3, VDAC2, } \\
\text { NDUFA1, NDUFA12 }\end{array}$ & 3 & 7 \\
\hline & mitochondrial matrix & GRPEL1, NDUFS8, PDHX, AGXT, NDUFS2, NDUFS1, PC & 4 & 3 \\
\hline & mitochondrial outer membrane & DNM1L, ACACB, VDAC2 & 2 & 1 \\
\hline & mitochondrial intermembrane space & NDUFB7, NDUFS1 & 0 & 2 \\
\hline \multirow[t]{7}{*}{$\begin{array}{l}\text { Molecular } \\
\text { function }\end{array}$} & NADH dehydrogenase (ubiquinone) activity & $\begin{array}{l}\text { NDUFB7, NDUFV1, NDUFA7, NDUFV2, NDUFS8, NDUFA1, NDUFS2, } \\
\text { NDUFA12, NDUFS1 }\end{array}$ & 0 & 9 \\
\hline & electron carrier activity & NDUFV2, AKR1B1, PHGDH, HAAO, SH3BGRL3, NDUFS2, NDUFA12, NDUFS1 & 2 & 6 \\
\hline & NAD binding & AHCY, SORD, NDUFV1, PHGDH, BDH2, NDUFS2 & 0 & 6 \\
\hline & NADH dehydrogenase activity & NDUFV1, NDUFS8, NDUFS2 & 0 & 3 \\
\hline & oxidoreductase activity, acting on $\mathrm{NAD}(\mathrm{P}) \mathrm{H}$ & NDUFS8, NDUFS2, NDUFS1 & 0 & 3 \\
\hline & oxidoreductase activity & PTGR2, SORD, NDUFV2, AKR1B1, ADH1C, BDH2 & 0 & 6 \\
\hline & $\begin{array}{l}\text { oxidoreductase activity, acting on the } \mathrm{CH}-\mathrm{CH} \\
\text { group of donors, NAD or NADP as acceptor }\end{array}$ & $\mathrm{SRD} 5 \mathrm{~A} 3, \mathrm{BDH} 2$ & 0 & 2 \\
\hline \multirow[t]{6}{*}{$\begin{array}{l}\text { Biological } \\
\text { process }\end{array}$} & $\begin{array}{l}\text { mitochondrial electron transport, NADH to } \\
\text { ubiquinone }\end{array}$ & $\begin{array}{l}\text { NDUFB11, NDUFB7, NDUFV1, NDUFA7, NDUFV2, NDUFS8, NDUFA1, } \\
\text { NDUFS2, NDUFA12, NDUFS1 }\end{array}$ & 0 & 10 \\
\hline & $\begin{array}{l}\text { mitochondrial respiratory chain complex I } \\
\text { assembly }\end{array}$ & $\begin{array}{l}\text { NDUFB11, NDUFB7, NDUFV1, NDUFA7, NDUFV2, NDUFS8, NDUFA1, } \\
\text { NDUFS2, NDUFA12, NDUFS1 }\end{array}$ & 0 & 10 \\
\hline & response to oxidative stress & EGFR, ALAD, ATOX1, NDUFS8, NDUFS2, NDUFA12, NAPRT & 1 & 6 \\
\hline & oxidation-reduction process & $\begin{array}{l}\text { PTGR2, SORD, CYP2B6, PCBD1, HGD, CRYL1, CBR1, PRDX6, AKR1B1, FMO3, } \\
\text { SRD5A3, HAAO, PHGDH, SH3BGRL3 }\end{array}$ & 3 & 11 \\
\hline & steroid metabolic process & CYP2B6, SULT1B1, SULT1A1, SULT1E1 & 0 & 4 \\
\hline & ATP synthesis coupled electron transport & NDUFA7, NDUFS1 & 0 & 2 \\
\hline
\end{tabular}

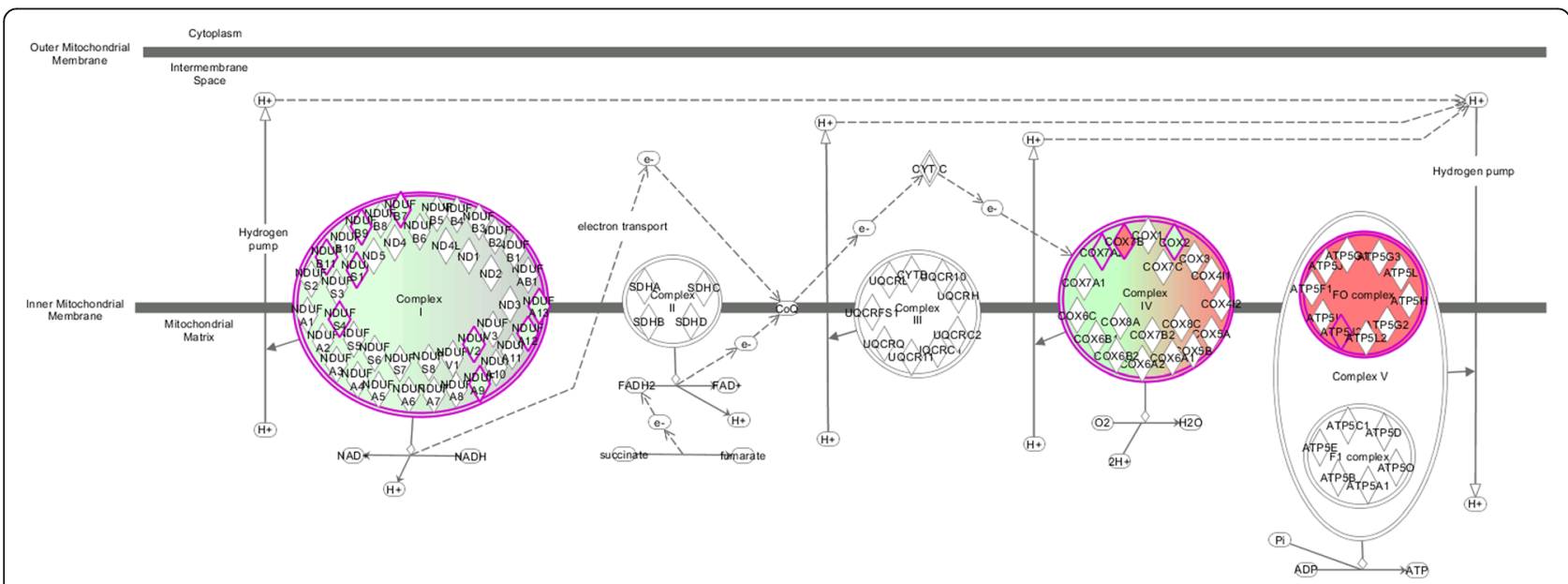

Fig. 4 Canonical Pathway diagram from Ingenuity Pathway Analysis: Oxidative phosphorylation was significantly inhibited. Colored boxes represent upregulation (red) and downregulation (green) in the PNALD 
semi-quantitative verification by western blotting, including CYP2B6, DDAH1, NDUFA1, FABP5, and CAPG (Fig. 5). As shown, expression of CYP2B6, DDAH1, and NDUFA1 was significantly downregulated, and that of FABP5 and CAPG was upregulated in the PNALD group, compared to the control group. Western blotting results were in agreement with iTRAQ proteomics results.

\section{Discussion}

Total parenteral nutrition is a life-saving therapy for patients with chronic gastrointestinal failure [49]. However, related metabolic complications, especially PNALD, arise with prolonged PN [50]. This study represents the firstever investigation of liver tissue proteomic profiles of patients with PNALD to identify potential biomarkers and elucidate the molecular alterations that occur following PNALD. We successfully identified 112 DEPs between PNALD and control groups. The number and interaction of DEPs indicated the mitochondrial oxidative phosphorylation damage, glycolipid metabolism disorder, and oxidative stress injury as primary biological changes occurring in PNALD. In addition, we performed western blot analysis and found the results matching perfectly with the iTRAQ proteomics data.

In our study, the cellular localization of DEPs (predicted using GO analysis) revealed most of the identified putative proteins to be localized in mitochondria, which may explain the disorders in glucose and lipid metabolism. Mitochondria are best known for harboring pathways involved in ATP synthesis through the tricarboxylic acid cycle and oxidative phosphorylation [51]. More than $80 \%$ of ATP is produced by mitochondrial oxidative phosphorylation. An earlier study had reported that TPN deteriorates hepatic mitochondrial function [52]. Consistent with this, our current study indicated that multiple subunits or components of the respiratory chain complex I assembly proteins, which are essential for oxidative phosphorylation in mitochondria [16], are downregulated in PNALD. This may affect the biosynthesis of ATP, which is necessary for the maintenance of liver function. Mean ATP levels in PN mouse model were found to be reduced as compared to those in an EN mouse, although there was no statistically significant difference between these levels [52]. Therefore, we speculated that PN might cause PNALD, at least in part, by damaging the respiratory chain complex I assembly.

Insulin resistance is one of the metabolic phenotypes found in nonalcoholic fatty liver disease but there is limited clinical evidence for insulin resistance associated with PNALD. One report in piglets had demonstrated that chronic TPN induces significant insulin resistance [29]. In agreement with the previous study, our results showed upregulated NNMT, which correlates positively with insulin resistance [53-55], and downregulated

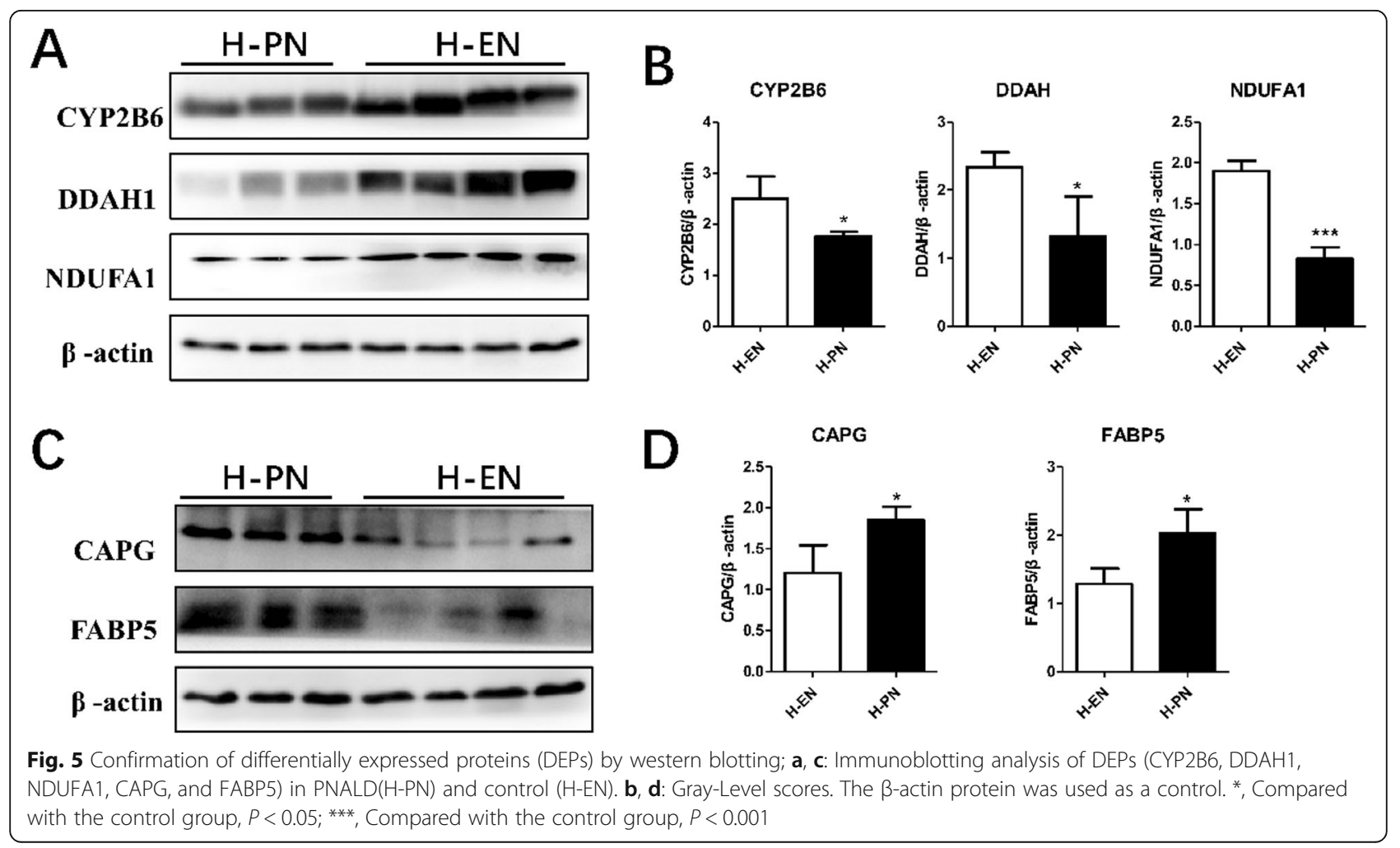


Table 3 KEGG pathways of differentially expressed proteins

\begin{tabular}{|c|c|c|c|c|c|c|}
\hline \multirow{2}{*}{$\begin{array}{l}\text { S. } \\
\text { No }\end{array}$} & & \multirow{2}{*}{$\begin{array}{l}\text { KEGG } \\
\text { ID }\end{array}$} & \multirow[t]{2}{*}{ Pathway } & \multicolumn{3}{|c|}{ Protein number } \\
\hline & & & & List & Up & Down \\
\hline 1 & Energy metabolism & 00190 & Oxidative phosphorylation & 11 & 1 & 10 \\
\hline \multirow[t]{8}{*}{2} & Carbohydrate metabolism & 01200 & Carbon metabolism & 8 & 2 & 6 \\
\hline & & 00030 & Pentose phosphate pathway & 4 & 0 & 4 \\
\hline & & 00040 & Pentose and glucuronate interconversions & 4 & 1 & 3 \\
\hline & & 00051 & Fructose and mannose metabolism & 4 & 1 & 3 \\
\hline & & 00010 & Glycolysis / Gluconeogenesis & 3 & 0 & 3 \\
\hline & & 00052 & Galactose metabolism & 2 & 1 & 1 \\
\hline & & 00520 & Amino sugar and nucleotide sugar metabolism & 2 & 1 & 1 \\
\hline & & 00620 & Pyruvate metabolism & 2 & 1 & 1 \\
\hline & & 00630 & Glyoxylate and dicarboxylate metabolism & 2 & 1 & 1 \\
\hline \multirow[t]{5}{*}{3} & Amino acid metabolism & 01230 & Biosynthesis of amino acids & 5 & 1 & 4 \\
\hline & & 00260 & Glycine, serin vitamin e and threonine metabolism & 5 & 1 & 4 \\
\hline & & 00340 & Histidine metabolism & 5 & 0 & 5 \\
\hline & & 00350 & Tyrosine metabolism & 3 & 0 & 3 \\
\hline & & 00250 & Alanine, aspartate and glutamate metabolism & 3 & 1 & 2 \\
\hline & & 00270 & Cysteine and methionine metabolism & 3 & 0 & 3 \\
\hline & & 00220 & Arginine biosynthesis & 2 & 0 & 2 \\
\hline \multirow[t]{3}{*}{4} & Lipid metabolism & 00590 & Arachidonic acid metabolism & 2 & 0 & 2 \\
\hline & & 00561 & Glycerolipid metabolism & 2 & 1 & 1 \\
\hline & & 00140 & Steroid hormone biosynthesis & 2 & 0 & 2 \\
\hline \multirow[t]{3}{*}{5} & Metabolism of cofactors and vitamins & 00790 & Folate biosynthesis & 4 & 1 & 3 \\
\hline & & 00760 & Nicotinate and nicotinamide metabolism & 2 & 1 & 1 \\
\hline & & 00830 & Retinol metabolism & 2 & 0 & 2 \\
\hline \multirow[t]{3}{*}{6} & Xenobiotics biodegradation and metabolism & 00982 & Drug metabolism - cytochrome P450 & 3 & 1 & 2 \\
\hline & & 00980 & Metabolism of xenobiotics by cytochrome P450 & 3 & 0 & 3 \\
\hline & & 00983 & Drug metabolism - other enzymes & 2 & 0 & 2 \\
\hline 7 & Nucleotide metabolism & 00240 & Pyrimidine metabolism & 2 & 0 & 2 \\
\hline \multirow[t]{3}{*}{8} & Signal transduction & 04020 & Calcium signaling pathway & 5 & 1 & 4 \\
\hline & & 04152 & AMPK signaling pathway & 3 & 0 & 2 \\
\hline & & 04151 & PI3K-Akt signaling pathway & 2 & 1 & 1 \\
\hline 9 & Nervous system & 04723 & Retrograde endocannabinoid signaling & 10 & 0 & 10 \\
\hline \multirow[t]{3}{*}{10} & Neurodegenerative diseases & 05012 & Parkinson's disease & 11 & 1 & 10 \\
\hline & & 05016 & Huntington's disease & 11 & 1 & 10 \\
\hline & & 05010 & Alzheimer's disease & 10 & 0 & 10 \\
\hline \multirow[t]{2}{*}{11} & Endocrine system & 04910 & Insulin signaling pathway & 6 & 0 & 6 \\
\hline & & 04922 & Glucagon signaling pathway & 5 & 0 & 5 \\
\hline 12 & Endocrine and metabolic diseases & 04932 & Non-alcoholic fatty liver disease (NAFLD) & 10 & 0 & 10 \\
\hline \multirow[t]{3}{*}{13} & Transport and catabolism & 04142 & Lysosome & 5 & 5 & 0 \\
\hline & & 04144 & Endocytosis & 2 & 0 & 2 \\
\hline & & 04145 & Phagosome & 2 & 2 & 0 \\
\hline \multirow[t]{3}{*}{14} & Cancers & 05204 & Chemical carcinogenesis & 3 & 0 & 3 \\
\hline & & 05205 & Proteoglycans in cancer & 2 & 1 & 1 \\
\hline & & 05200 & Pathways in cancer & 2 & 0 & 2 \\
\hline
\end{tabular}


Table 3 KEGG pathways of differentially expressed proteins (Continued)

\begin{tabular}{|c|c|c|c|c|c|c|}
\hline \multirow{2}{*}{$\begin{array}{l}\text { S. } \\
\text { No. }\end{array}$} & & \multirow{2}{*}{$\begin{array}{l}\text { KEGG } \\
\text { ID }\end{array}$} & \multirow[t]{2}{*}{ Pathway } & \multicolumn{3}{|c|}{ Protein number } \\
\hline & & & & List & Up & Down \\
\hline \multirow[t]{3}{*}{15} & Cell growth and death & 04114 & Oocyte meiosis & 2 & 1 & 1 \\
\hline & & 04110 & Cell cycle & 2 & 1 & 1 \\
\hline & & 04217 & Necroptosis & 2 & 2 & 0 \\
\hline 16 & Cell motility & 04810 & Regulation of actin cytoskeleton & 2 & 1 & 1 \\
\hline \multirow[t]{3}{*}{17} & Immune system & 04612 & Antigen processing and presentation & 2 & 2 & 0 \\
\hline & & 04621 & NOD-like receptor signaling pathway & 2 & 2 & 0 \\
\hline & & 04610 & Complement and coagulation cascades & 2 & 2 & 0 \\
\hline 18 & Infectious diseases & 05120 & Epithelial cell signaling in Helicobacter pylori infection & 2 & 1 & 1 \\
\hline 19 & Digestive system & 04976 & Bile secretion & 2 & 0 & 2 \\
\hline 20 & Excretory system & 04966 & Collecting duct acid secretion & 2 & 1 & 1 \\
\hline
\end{tabular}

GNMT, deficiency of which is known to impair glucose tolerance and insulin sensitivity. Furthermore, KEGG analysis indicated the DEPs to be associated with the insulin signaling pathway and PI3K-Akt signaling pathway (Table 3). These results together suggested that insulin sensitivity was impaired in patients with PNALD. Insulin resistance was also implicated by mitochondrial dysfunction or mitochondrial oxidative stress [56]. Mitochondrial oxidative phosphorylation was hampered, proteins with antioxidant function, including PRDX6, RGN, PHGDH, ALAD, GOT1, and DDAH1, were downregulated in patients with PNALD, and production of reactive oxygen species was increased, eventually leading to oxidative stress. Consistent with these results, several studies have demonstrated the impaired capacity of antioxidants during TPN [57, 58], and indicated oxidative stress play an important role in the development of PNALD [59, 60].

Our results indicated that LGALS3 (Table S1), which contributes to inflammatory injury and fibrogenesis in cholestatic liver injury [61], was upregulated, and that DEPs were associated with NOD-like receptor signaling pathway. IPA results showed that the "LPS/IL-1 mediated inhibition of RXR function" pathway was activated (Fig. S2). Inflammation triggered by macrophages induced obesity related insulin resistance [62]. Consistent with these results, previous studies had indicated that LPS-mediated macrophages and IL- $1 \beta$ production or LPS-activated Kupffer cell through TLR4 might be early events in the pathogenesis of PNALD [63, 64].

A limitation of this study was an insufficient number of subjects, due to the extreme rarity of PNALD and infrequent source of liver tissue. Although previous studies had reported the abnormal glycolipid metabolism and oxidative stress in TPN, this is the first study that revealed damaged mitochondrial oxidative phosphorylation in patients with PNALD and provided a new target for exploring the mechanism and treatment of PNALD.
In conclusion, we identified several biological abnormalities that occur in patients with PNALD, such as in glycolipid metabolism, mitochondrial oxidative phosphorylation, and oxidative stress. We also detected the involvement of insulin and inflammatory signaling in PNALD pathogenesis. Our results provided new insights into the changes that occur in PNALD, and further identified candidate proteins as future PNALD biomarkers or therapeutic targets.

\section{Supplementary information}

Supplementary information accompanies this paper at https://doi.org/10. 1186/s12986-020-00453-z.

Additional file 1. Supplementary information: Supplementary tables and other bioinformation analysis (Annotation Enrichment Analysis, Different Proteins Analysis, Hierarchical Clustering Analysis, KEGG Analysis and, Network Analysis and Ingenuity Pathway Analysis) were listed in the file.

\section{Abbreviations}

PN: Parenteral nutrition; PNALD: Parenteral nutrition-associated liver disease iTRAQ: Isobaric Tag for Relative and Absolute Quantitation; GO: Gene Ontology; KEGG: Kyoto Encyclopedia of Genes and Genomes; DEPS: Differentially expressed proteins; TPN: Total parenteral nutrition; MF: Molecular functions; BP: Biological processes; CC: Cellular components; ACACB: Acetyl-CoA carboxylase 2; AKR1B1: Aldose reductase; ALAD: Deltaaminolevulinic acid dehydratase; AMDHD1: Probable imidazolonepropionase; CAPG: Macrophage-capping protein; CPPED1: Serine/threonine-protein phosphatase; CTSS: Cathepsin S; CYP2B6: Cytochrome P450 2B6; N(G)dimethylarginine: $\mathrm{N}(\mathrm{G})$; DDAH1: Dimethylaminohydrolase 1; EIF2: Eukaryotic translation initiation factor 2 subunit 1; FABP5: Fatty acid-binding protein FBP1: Fructose-1,6-bisphosphatase 1; FBP2: Fructose-1,6-bisphosphatase isozyme 2; FTCD: Formimidoyltransferase-cyclodeaminase; GNMT: Glycine Nmethyltransferase; GOT1: Aspartate aminotransferase; GOT1: Aspartate aminotransferase cytoplasmic; HAL: Histidine ammonia-lyase; HNMT: Histamine N-methyltransferase; IL-1ß: Interleukin-1 $\beta$; iTRAQ: Relative and Absolute Quantitation; IPA: Ingenuity Pathway Analysis;

LGALS3: Galectin-3; LPS: Lipopolysaccharide; MF: Molecular function; NRF2: Nuclear factor erythroid 2-related factor 2 9.; NDUFA1: NADH dehydrogenase [ubiquinone] 1 alpha subcomplex subunit 1;

NDUFA 12: NADH dehydrogenase [ubiquinone] 1 alpha subcomplex subunit 12; NDUFA7: NADH dehydrogenase [ubiquinone] 1 alpha subcomplex subunit 7; NDUFB11: NADH dehydrogenase [ubiquinone] 1 beta subcomplex subunit 11; NDUFB7: NADH dehydrogenase [ubiquinone] 1 beta subcomplex 
subunit 7; NDUFS1: NADH-ubiquinone oxidoreductase $75 \mathrm{kDa}$ subunit mitochondrial; NDUFS2: NADH dehydrogenase [ubiquinone] iron-sulfur protein 2; NDUFS8: NADH dehydrogenase [ubiquinone] iron-sulfur protein 8; NDUFV1: NADH dehydrogenase [ubiquinone] flavoprotein 1; NDUFV2: NADH dehydrogenase [ubiquinone] flavoprotein 2 mitochondrial; NNMT: Nicotinamide N-methyltransferase; PFKFB4: 6-phosphofructo-2-kinase/ fructose-2,6-bisphosphatase 4; PC: Pyruvate carboxylase; PHGDH: D-3phosphoglycerate dehydrogenase; PHKA2: Phosphorylase b kinase regulatory subunit alpha liver isoform; PHKB: Phosphorylase $b$ kinase regulatory subunit beta; PHKG2: Phosphorylase b kinase gamma catalytic chain liver/testis isoform; PRDX6: Peroxiredoxin-6; RGN: Regucalcin; ROS: Reactive oxygen species; SULT1E1: Estrogen sulfotransferase; TLR4: Toll-like receptor 4; TPN: Total parenteral nutrition; UROC1: Urocanate hydratase

\section{Acknowledgements}

We express our gratitude to all of the participants who consented to participate in this study.

\section{Authors' contributions}

W.X.Y. and T.F. designed the study. T.F., S.H.F., Z.L., and G.X.J. collected the samples. M.G. performed the experiments. M.G. and S.H.F. analyzed the data and wrote the manuscript. W.X.Y. and X.B. reviewed/edited the manuscript. W.X.Y. and X.B. supervised the research. All authors read and approved the final manuscript.

\section{Funding}

This work gained support from the National Natural Science Foundation of China (General Program, 81770531), the Excellent Youth Foundation Project of Jiangsu Province (BK20170009), the Key Medical Talents Foundation of Jiangsu Province (ZDRCA2016091), the National Natural Science Foundation of China $(81700518,81900524)$, the Natural Science Foundation of Jiangsu Province (BK20170622), Natural Science Foundation of Shandong Province (ZR2019BH010) and the Chinese National Science Foundation (31371373).

\section{Availability of data and materials}

All data generated or analyzed during this study are included in this published article (and its supplementary information files).

\section{Ethics approval and consent to participate}

All subjects gave their informed consent for inclusion before they participated in the study. The study was approved by the Ethics Committee of the Jinling hospital, Medical School of Nanjing University (2017NZGKJ071).

\section{Consent for publication}

Not applicable.

\section{Competing interests}

The authors declare that they have no competing interests.

Received: 31 December 2019 Accepted: 13 April 2020

Published online: 03 June 2020

\section{References}

1. Stanghellini V. CRDG: natural history of intestinal failure induced by chronic idiopathic intestinal pseudo-obstruction. Transplant Proc. 2010;42:15-8.

2. Triantafillidis JK, Papalois AE. The role of total parenteral nutrition in inflammatory bowel disease: current aspects. Scand J Gastroenterol. 2014;49:3-14

3. Ekema G, Milianti S, Boroni G. Total parenteral nutrition in patients with short bowel syndrome. Minerva Pediatr. 2009;61:283-91.

4. Beath SV, Kelly DA. Total parenteral nutrition-induced cholestasis: prevention and management. Clinics in Liver Disease. 2016;20:159-76.

5. Orso G, Mandato C, Veropalumbo C, Cecchi N, Garzi A, Vajro P. Pediatric parenteral nutrition-associated liver disease and cholestasis: Novel advances in pathomechanisms-based prevention and treatment. Dig Liver Dis. 2016; 48:215-22.

6. Sigalet D, Boctor D, Robertson M, Lam V, Brindle M, Sarkhosh K, Driedger L, Sajedi M. Improved outcomes in paediatric intestinal failure with aggressive prevention of liver disease. Eur J Pediatr Surg. 2009;19:348-53.
7. Koseesirikul P, Chotinaruemol S, Ukarapol N. Incidence and risk factors of parenteral nutrition-associated liver disease in newborn infants. Pediatr Int 2012;54:434-6.

8. Anez-Bustillos L, Dao DT, Baker MA, Fell GL, Puder M, Gura KM. Intravenous Fat Emulsion Formulations for the Adult and Pediatric Patient: Understanding the Differences. Nutr Clin Pract. 2016;31:596-609.

9. Denton C, Price A, Friend J, Manithody C, Blomenkamp K, Westrich M, Kakarla V, Phillips W, Krebs J, Munoz SA, Osei H, Jain AK. Role of the Gut ${ }^{-}$Liver Axis in Driving Parenteral Nutrition-Associated Injury. Children (Basel, Switzerland). 2018:5:136.

10. Anderson NL, Anderson NG. Proteome and proteomics: new technologies, new concepts, and new words. Electrophoresis. 1998;19:1853-61.

11. Le Zhan IY, Kong B, Shen J, Gorczyca L, Memon N, Buckley BT, Guo GL. Dysregulation of bile acid homeostasis in parenteral nutrition mouse model. Am J Physiol Gastrointest Liver Physiol. 2016;310:G93-G102.

12. Beath SV, Kelly DA. Total parenteral nutrition-induced cholestasis. Clin Liver Dis. 2016:20:159-76.

13. UniProt: a hub for protein information. Nucleic Acids Res. 2015;43:D204-12.

14. Dennis G Jr, Sherman BT, Hosack DA, Yang J, Gao W, Lane HC, Lempicki RA. DAVID: Database for Annotation, Visualization, and Integrated Discovery. Genome Biol. 2003:4:P3.

15. Chaban Y, Boekema EJ, Dudkina NV. Structures of mitochondrial oxidative phosphorylation supercomplexes and mechanisms for their stabilisation. Biochimica et Biophysica Acta (BBA) - Bioenergetics. 2014; 1837:418-26.

16. Formosa LE, Dibley MG, Stroud DA, Ryan MT. Building a complex complex: assembly of mitochondrial respiratory chain complex I. Semin Cell Dev Biol. 2018;76:154-62

17. Skamnaki VT, Owen DJ, Noble MEM, Lowe ED, Lowe G, Oikonomakos NG, Johnson LN. Catalytic mechanism of Phosphorylase kinase probed by mutational studiest,‡. Biochemistry. 1999;38:14718-30.

18. Kaur R, Dahiya L, Kumar M. Fructose-1,6-bisphosphatase inhibitors: a new valid approach for management of type 2 diabetes mellitus. Eur J Med Chem. 2017:141:473-505.

19. Jitrapakdee S, St Maurice M, Rayment I, Cleland WW, Wallace JC, Attwood PV. Structure, mechanism and regulation of pyruvate carboxylase. Biochem J. 2008;413:369-87.

20. Kumashiro N, Beddow SA, Vatner DF, et al. Targeting Pyruvate Carboxylase Reduces Gluconeogenesis and Adiposity and Improves Insulin Resistance. Diabetes. 2013:62(7):2183-94.

21. Pissios P. Nicotinamide $\mathrm{N}$-methyltransferase: more than a vitamin B3 clearance enzyme. Trend Endocrinol Metab. 2017;28:340-53.

22. Okabe K, Usui I, Yaku K, Hirabayashi Y, Tobe K, Nakagawa T. Deletion of $\mathrm{PHGDH}$ in adipocytes improves glucose intolerance in diet-induced obese mice. Biochem Biophys Res Commun. 2018;504:309-14.

23. Vaittinen M, Kaminska D, Kakela P, Eskelinen M, Kolehmainen M, Pihlajamaki J, Uusitupa M, Pulkkinen L. Downregulation of CPPED1 expression improves glucose metabolism in vitro in adipocytes. Diabetes. 2013:62:3747-50.

24. Nguyen P, Leray V, Diez M, Serisier S, Bloc HJL, Siliart B, Dumon H. Liver lipid metabolism. J Anim Physiol Anim Nutr. 2008;92:272-83.

25. Wada T, Ihunnah CA, Gao J, Chai X, Zeng S, Philips BJ, Rubin JP, Marra KG, Xie W. Estrogen Sulfotransferase inhibits adipocyte differentiation. Mol Endocrinol. 2011;25:1612-23.

26. Ihunnah CA, Wada T, Philips BJ, Ravuri SK, Gibbs RB, Kirisci L, Rubin JP, Marra KG, Xie W. Estrogen Sulfotransferase/SULT1E1 Promotes Human Adipogenesis. Mol Cell Biol. 2014;34:1682-94.

27. Murea M, Freedman BI, Parks JS, Antinozzi PA, Elbein SC, Ma L. Lipotoxicity in diabetic nephropathy: the potential role of fatty acid oxidation. Clin J Am Soc Nephrol. 2010;5:2373-9.

28. Chen YM, Shiu JY, Tzeng SJ, Shih LS, Chen YJ, Lui WY, Chen PH. Characterization of glycine- $\mathrm{N}$-methyltransferase-gene expression in human hepatocellular carcinoma. Int J Cancer. 1998;75:787-93.

29. Stoll B, Horst DA, Cui L, Chang X, Ellis KJ, Hadsell DL, Suryawan A, Kurundkar A, Maheshwari A, Davis TA, Burrin DG. Chronic parenteral nutrition induces hepatic inflammation, Steatosis, and insulin resistance in neonatal pigs. J Nutr. 2010;140:2193-200

30. Liao YJ, Chen TL, Lee TS, Wang HA, Wang CK, Liao LY, Liu RS, Huang SF, Chen YM. Glycine N-methyltransferase deficiency affects Niemann-pick type C2 protein stability and regulates hepatic cholesterol homeostasis. Mol Med. 2012;18:412-22 
31. Liu S, Li Y, Chen Y, Chiang E, Li AF, Lee Y, Tsai T, Hsiao M, Hwang S, Chen YA. Glycine N-methyltransferase-/- mice develop chronic hepatitis and glycogen storage disease in the liver. Hepatology. 2007; 46:1413-25.

32. Martínez-Chantar ML, Vázquez-Chantada M, Ariz U, Martínez N, Varela M, Luka Z, Capdevila A, Rodríguez J, Aransay AM, Matthiesen R, Yang H, Calvisi DF, Esteller M, Fraga M, Lu SC, Wagner C, Mato JM. Loss of the glycine Nmethyltransferase gene leads to steatosis and hepatocellular carcinoma in mice. Hepatology. 2008:47:1191-9.

33. Hotamisligil GS, Bernlohr DA. Metabolic functions of FABPs--mechanisms and therapeutic implications. Nat Rev Endocrinol. 2015;11:592-605.

34. Reißhauer A, Elmer N, Liebl ME. Multiple Statistical Methods for Assessing Differential Gene Expression in Microarray Data of Diabetic Model Rats to Predict the Molecular Mechanism of Atorvastatin on Anti-Atherogenesis. Exp Clin Endocrinol Diabetes. 2013;121(05):272-9.

35. Brown KE, Broadhurst KA, Mathahs MM, Kladney RD, Fimmel CJ, Srivastava SK, Brunt EM. Immunodetection of aldose reductase in normal and diseased human liver. Histol Histopathol. 2005;20:429-36.

36. Li T, Feng R, Zhao C, Wang Y, Wang J, Liu S, Cao J, Wang H, Wang T, Guo Y, Lu Z. Dimethylarginine Dimethylaminohydrolase 1 protects against high-fat diet-induced hepatic Steatosis and insulin resistance in mice. Antioxid Redox Signal. 2017;26:598-609.

37. Chow J, Rahman J, Achermann JC, Dattani MT, Rahman S. Mitochondrial disease and endocrine dysfunction. Nat Rev Endocrinol. 2017;13:92-104.

38. Patel P, Chatterjee S. Peroxiredoxin6 in endothelial signaling. Antioxidants. 2019;8:63.

39. Yamaguchi M, Murata T. Involvement of regucalcin in lipid metabolism and diabetes. Metabolism. 2013:62:1045-51.

40. Pereira B, Curi R, Kokubun E, Bechara EJ. 5-aminolevulinic acid-induced alterations of oxidative metabolism in sedentary and exercise-trained rats. J Appl Physiol(Bethesda, Md. 1985). 1992;72:226-30.

41. Vandekeere S, Dubois C, Kalucka J, Sullivan MR, García-Caballero M, Goveia J, Chen R, Diehl FF, Bar-Lev L, Souffreau J, Pircher A, Kumar S, Vinckier S, Hirabayashi Y, Furuya S, Schoonjans L, Eelen G, Ghesquière B, Keshet E, Li X. Serine synthesis via PHGDH is essential for Heme production in endothelial cells. Cell Metab. 2018;28:573-87.

42. Hong C, Zheng J, Li X. Inhibition of GOT1 sensitizes colorectal cancer cells to 5-fluorouracil. Cancer Chemother Pharmacol. 2017;79:835-40.

43. Zhao C, Li T, Han B, Yue W, Shi L, Wang H, Guo Y, Lu Z. DDAH1 deficiency promotes intracellular oxidative stress and cell apoptosis via a miR-21dependent pathway in mouse embryonic fibroblasts. Free Radic Biol Med. 2016:92:50-60

44. Ommati MM, Jamshidzadeh A, Heidari R, Sun Z, Zamiri MJ, Khodaei F, Mousapour S, Ahmadi F, Javanmard N, Shirazi Yeganeh B. Carnosine and Histidine supplementation blunt Lead-induced reproductive toxicity through Antioxidative and mitochondria-dependent mechanisms. Biol Trace Elem Res. 2019:187:151-62.

45. Kubben N, Zhang W, Wang L, Voss TC, Yang J, Qu J, Liu G, Misteli T. Repression of the antioxidant NRF2 pathway in premature aging. Cell. 2016; 165:1361-74.

46. Dang CV. Cancer cell metabolism: there is no ROS for the weary: figure 1 . Cancer Discovery. 2012;2:304-7.

47. Chen J. Regulation of protein synthesis by the heme-regulated elF2a kinase: relevance to anemias. Blood. 2006;109:2693-9.

48. Ferrucci-Da Silva C, Zhan L, Shen J, Kong B, Campbell MJ, Memon N, Hegyi T, Lu L, Guo GL. Effects of total parenteral nutrition on drug metabolism gene expression in mice. Acta Pharm Sin B. 2020;10:153-8.

49. Dudrick SJ, Palesty JA. Historical highlights of the development of Total parenteral nutrition. Surg Clin North Am. 2011;91:693-717.

50. Mutanen A, Lohi J, Heikkilä P, Jalanko H, Pakarinen MP. Liver inflammation relates to decreased Canalicular bile transporter expression in pediatric onset intestinal failure. Ann Surg. 2017;268:1.

51. van der Bliek AM, Sedensky MM, Morgan PG. Cell biology of the mitochondrion. Genetics. 2017:207:843-71.

52. Katayama T, Tanaka M, Tanaka K, Asonuma K, Uemoto S, Okamura R, Utsunomiya H, Fujita S, Ueda J, Tanaka A, Ozawa K. Alterations in hepatic mitochondrial function during Total parenteral nutrition in immature rats. J Parenter Enter Nutr. 1990;14:640-5.

53. Riederer M, Erwa W, Zimmermann R, Frank S, Zechner R. Adipose tissue as a source of nicotinamide $\mathrm{N}$-methyltransferase and homocysteine. Atherosclerosis. 2009;204:412-7.
54. Kannt A, Pfenninger A, Teichert $L$, Tönjes A, Dietrich A, Schön MR, Klöting N, Blüher M. Association of nicotinamide-N-methyltransferase mRNA expression in human adipose tissue and the plasma concentration of its product, 1-methylnicotinamide, with insulin resistance. Diabetologia. 2015; 58:799-808.

55. Kraus D, Yang Q, Kong D, Banks AS, Zhang L, Rodgers JT, Pirinen $E_{\text {, }}$ Pulinilkunnil TC, Gong F, Wang Y, Cen Y, Sauve AA, Asara JM, Peroni OD Monia BP, Bhanot S, Alhonen L, Puigserver P, Kahn BB. Nicotinamide Nmethyltransferase knockdown protects against diet-induced obesity. Nature. 2014;508:258-62.

56. Fazakerley DJ, Minard AY, Krycer JR, Thomas KC, Stöckli J, Harney DJ, Burchfield JG, Maghzal GJ, Caldwell ST, Hartley RC, Stocker R, Murphy MP, James DE. Mitochondrial oxidative stress causes insulin resistance without disrupting oxidative phosphorylation. J Biol Chem. 2018;293:7315-28.

57. Matilla B, Ortíz J, González P, García-Díez F, Jorquera F, Culebras JM, González-Gallego J, Tuñón MJ. Effects of parenteral nutrition supplemented with glutamine or glutamine dipeptides on liver antioxidant and detoxication systems in rats. Nutrition. 2000;16:125-8.

58. Sokol RJ, Taylor SF, Devereaux MW, Khandwala R, Sondheimer NJ, Shikes RH Mierau G. TWFB: hepatic oxidant injury and glutathione depletion during total parenteral nutrition in weanling rats. Am J Phys. 1996;270:G691-700.

59. Staun M, Pironi L, Bozzetti F, Baxter J, Forbes A, Joly F, Jeppesen P, Moreno J, Hébuterne X, Pertkiewicz M, Mühlebach S, Shenkin A, Van Gossum A. ESPEN guidelines on parenteral nutrition: home parenteral nutrition (HPN) in adult patients. Clin Nutr. 2009;28:467-79.

60. Cai W, Wu J, Hong L, Xu Y, Tang Q, Shi C. Oxidative injury and hepatocyte apoptosis in total parenteral nutrition-associated liver dysfunction. J Pediatr Surg. 2006;41:1663-8.

61. Tian J, Yang G, Chen H, Hsu DK, Tomilov A, Olson KA, Dehnad A, Fish SR, Cortopassi G, Zhao B, Liu F, Gershwin ME, Török NJ, Jiang JX. Galectin-3 regulates inflammasome activation in cholestatic liver injury. FASEB J. 2016; 30:4202-13.

62. Lauterbach MAR, Wunderlich FT. Macrophage function in obesity-induced inflammation and insulin resistance. Pflugers Arch - Eur J Physiol. 2017:469: 385-96.

63. El Kasmi KC, Vue PM, Anderson AL, Devereaux MW, Ghosh S, Balasubramaniyan N, Fillon SA, Dahrenmoeller C, Allawzi A, Woods C, McKenna S, Wright CJ, Johnson L, D Alessandro A, Reisz JA, Nozik-Grayck E, Suchy FJ, Sokol RJ. Macrophage-derived IL-1B/NF-KB signaling mediates parenteral nutrition-associated cholestasis. Nat Commun. 2018;9:1393.

64. El Kasmi KC, Anderson AL, Devereaux MW, Fillon SA, Harris JK, Lovell MA, Finegold MJ, Sokol RJ. Toll-like receptor 4-dependent Kupffer cell activation and liver injury in a novel mouse model of parenteral nutrition and intestinal injury. Hepatology. 2012;55:1518-28.

\section{Publisher's Note}

Springer Nature remains neutral with regard to jurisdictional claims in published maps and institutional affiliations.

\section{Ready to submit your research? Choose BMC and benefit from:}

- fast, convenient online submission

- thorough peer review by experienced researchers in your field

- rapid publication on acceptance

- support for research data, including large and complex data types

- gold Open Access which fosters wider collaboration and increased citations

- maximum visibility for your research: over $100 \mathrm{M}$ website views per year

At $\mathrm{BMC}$, research is always in progress.

Learn more biomedcentral.com/submission 